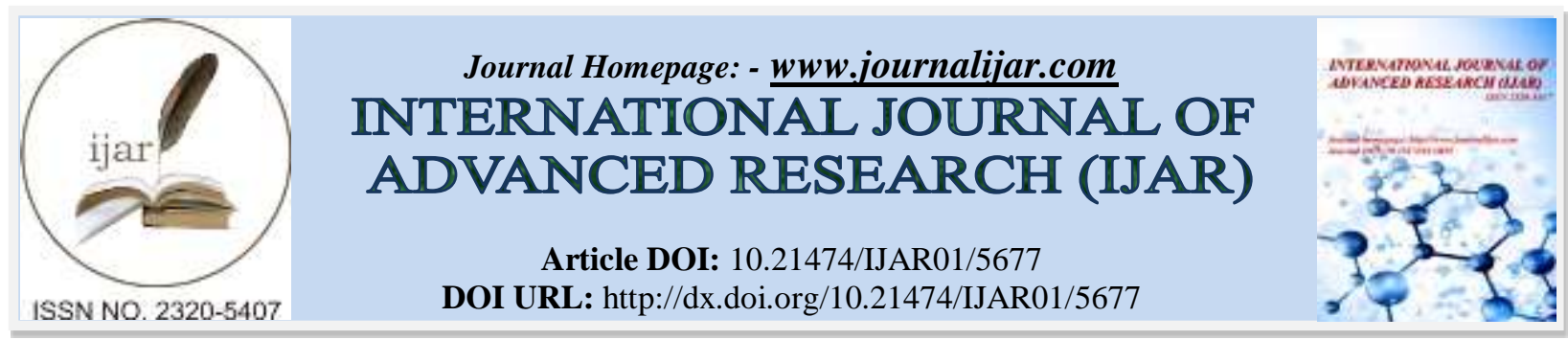

RESEARCH ARTICLE

\title{
FACTORS CONTRIBUTING TO QUALITY OF LIFE AMONG PEOPLE LIVING WITH HIV/AIDS RECEIVING ANTI-RETROVIRAL THERAPY: A CROSS-SECTIONAL STUDY.
}

\section{"Rajiv D. Limbasiya ${ }^{1}$, Dr. M. M. Prabhakar ${ }^{2}$ and Dr. Rajendra Gadhavi ${ }^{3}$.}

1. Lecturer, The Sarvajanik College of Physiotherapy, Surat.

2. Additional Director, medical education, and research, Gandhinagar, Medical Superintendent Civil Hospital, Ahmedabad, HOD, Orthopaedic Department, Civil Hospital, Ahmedabad.

3. Deputy Director, GSACS, Department of Health and Family welfare, Govt. of Gujarat.

\section{Manuscript Info}

Manuscript History

Received: 20 August 2017

Final Accepted: 22 September 2017

Published: October 2017

Key words:-

Quality of life, HIV/AIDS,

Antiretroviral therapy, FAHI.

\section{Abstract}

Background: Human immunodeficiency Virus (HIV)/Acquired Immunodeficiency Syndrome (AIDS) is a fatal illness which leaves the victim vulnerable and builds a vacuum in a person affecting his/her life as a whole. Quality of life (QOL) is an important component in the evaluation of the well-being of people living with HIV and AIDS (PLWHA) as it affects an individual physically, socially, emotionally, mentally and financially.

Objectives: This study was undertaken to assess the impact of sociodemographic and clinical factors on QOL in PLWHA.

Methodology: A cross-sectional study was performed on 110 individuals came to Community care and Support Centre (CSC), Surat from June 2016 to March 2017. Purposive sampling technique was used for selection of participants. QOL life was assessed with the FAHI (Functional Assessment of HIV Infection) instrument. The sociodemographic factors were also obtained in a pre-designed proforma. The data were analyzed using descriptive statistics, Pearson's correlation and One-Way Analysis of Variance (ANOVA) tests.

Results: The results showed that there were $66 \%$ males and $40 \%$ were females. The mean age of the participants was $41.27 \pm 8.44$ years. The mean FAHI score was $132.97 \pm 20.23$. If the mean domain scores were taken as the percentage of the highest score for their respective domain, the subjects scored most poorly in the emotional domain (66\%) than the social domain $(76 \%)$ which closely followed by functional and global domain $(77 \%)$. The participants seemed to be the best in the physical well-being (PWB) domain of FAHI. There was no significant difference in FAHI score between duration of illness, duration of taking ART (Antiretroviral therapy) and CD4 count.

Conclusion: It was found that social well-being (SWB), functional and global well-being (FGWB) and cognitive functioning (CF) were controlled by the demographical or clinical variable such as living arrangement, marital status, and duration of taking ART. Even though PLHAs had better scores in physical and cognitive functioning domains they face difficulties in their emotional aspects. 


\section{Introduction:-}

With a disturbing increment of Human Immunodeficiency Virus(HIV)/Acquired Immunodeficiency Syndrome (AIDS) in developing countries (evaluated pervasiveness in India $=0.91 \%$ ) and failure to manage the cost of exceedingly dynamic against retroviral treatment, key issues like the quality of life (QOL) have gone to the fore. Deciding the effect on the QOL in HIV/AIDS patients is imperative for assessing the burden of the sickness. This is genuine on the grounds that AIDS has an incessant weakening course and the long haul antagonistic symptoms of current medications modalities are questionable. The social shame connected with the declaration of HIV seropositive may on occasion drive the person to change the employment or the place of living, putting further weight on the officially frail financial circumstance. This further prompts dynamic decay of wellbeing, low resolve, rehashed meeting, restraint from work and low efficiency. The endless loop subsequently goes on, financial hardship and social seclusion takes it tolls on the personal satisfaction. (Naveet et al. 2006)

Quality of life is a multi-dimensional concept whose definition and assessment remains controversial. (Susan et al. ${ }^{1999)}$ There are many factors that impact the QOL in people living with HIV-AIDS (PLHIV).Past studies have analysed the connections between health-related quality of life (HRQOL) and depression, family and social support, HIV positive stage, working in daily living, vocational status, health status, and severity of HIV infection symptoms, stress and side effect of medications for HIV contamination among subjects living with HIV positive. (Murri et al. 2003) (Yen et al. 2004). Viral load and QOL were negatively correlated in PLHIV attending out-patient clinics ${ }^{(C a l l}$ et al. 2000)

HRQOL consists of the ability to perform daily activities, such as walking and working, and well-being, or lack thereof, because of health. It covers broad aspects of physical and mental health that are rarely assessed directly in routine medical encounters. (Wilson \& Cleary ${ }^{1995)}$ HIV infection is an important chronic condition in which to study HRQOL and survival, because of the myriad mental and physical manifestations over the course of the illness, and because of the high mortality rate. Both clinical trials and observational studies of persons with HIV infection often include HRQOL measures to evaluate the simultaneous effects of clinical interventions, treatment side effects, and disease impact over time. (Ganz et al. 1994) (Globe, Hays \& Cunningham 1999) (Wu et al. 1997) (Bozzette et al. 1995) Some studies have also shown a relation of HRQOL with laboratory and other clinical end points. (Chan \& Revicki 1998)

The data from research conducted in local population will more realistically re-orientate policy maker in addressing the issue of improving the aspects of HIV psycho-education, infection control and the standard of care and rehabilitation of PLHIV. Considering the prevalence and spread of HIV in India and limited availability of treatment modalities it seems necessary to assess QOL in such population.

Thus, the purpose of our study was to determine whether socio-demographic, clinical factors have any influence on the QOL of PLHIV.

\section{Methods:-}

\section{Study design and setting:-}

A cross-sectional study design was used and the sample recruitment was done by convenience sampling method. The study population was the consecutive patients attending the community care and support center, Surat within a period of 10 months (From June 2016-March 2017). Individuals with confirmatory serology results, physician's diagnosis, aged between 18 and 59 years and duration of illness for at least one year from the date of illness notification were included in the study. While individuals with a co-morbid medical condition unrelated to HIV and pregnancy were excluded. Total 110 patients were consecutively selected after they had signed informed consent.

\section{Questionnaires:-}

The instruments used in this study were (1) Socio-demographic and clinical variables form; (2) Functional Assessment of Human Immunodeficiency Virus Infection (FAHI). This FAHI questionnaire was part of the Functional Assessment of Chronic Illness Therapy (FACIT) that was developed and improved since 1997 by the Centre on Outcomes, Research and Education (CORE).It measures QOL on the following sub-scales: physical wellbeing (13 items), emotional well-being (10items), function and global well-being (13 items), social well-being (8 items), cognitive functioning (3 items) and three items reflecting both general illness and HIV/AIDS-specific QOL concerns. This instrument has been shown to have a good internal consistency ( 0.91 for the total scale and ranging 
from 0.73 to 0.90 for the sub-scales), has strong construct validity and known group's validity and is sensitive to change (Peterman, Cella \& McCain 1997) (Unsupported source type (InternetSite) for source FAC16.)

Socio-demographic variables measured were: age, gender, marital status, level of educational, types of occupation, income level, alcohol consumption and migration. Clinical variables were: Duration of illness, duration of taking ART and CD4 cell count. The Ethical approval was taken from the institutional ethical committee, Sarvajanik College of physiotherapy and a written permission was also taken from the NACO.

Data collection: After signing the informed consent, patients were interviewed for FAHI questionnaires. They were given enough time for giving the answer. The investigator was available to provide assistance when needed, without influencing patients' answers. The same investigator obtained the socio-demographic and clinical information from patients' medical records.

Data entry and statistical analyses: All data were entered and analyzed using the Statistical Package for Social Science (SPSS) software. The dependent variables were the scores of each sub-scale and the total score of FAHI. Descriptive statistics were calculated for all the outcome variables and were expressed as mean (SD) and frequency (\%) as appropriate. Pearson correlation was done to find out how all five domains score of FAHI was related to total FAHI score. One-way analysis of variance was done between domains of FAHI and categories of demographic and clinical variables.

\section{Results:-}

A total of 110 PLHIV were included in the study, of whom 66 were male $(66 \%)$ and 44 were female (40\%). The mean age of the group was $41.27 \pm 8.44$ years, and the median age was 40.50 years. The mean age of the male patients was 42.85 years and that of the female patients was 38.91 years; this difference was significant. A summary of the socio-demographic with mean FAHI value is presented in Table 1. Male subjects were slightly more than female subjects $(60 \%-40 \%)$, and least number of the patients were in the age group of 18-30years.More than two third of the patients were married and stayed with their spouses and children. Very few respondents were unemployed (9\%) and near half of the population had monthly incomes between 5000 to 10,000 INR. Mean score of FAHI based on clinical variables is described in Table 2.

Table 1:- Mean score of FAHI questionnaire, based on the socio-demographic variables $(\mathrm{n}=110)$

\begin{tabular}{|c|c|c|c|c|}
\hline \multirow{2}{*}{\multicolumn{2}{|c|}{ Variable }} & \multirow[t]{2}{*}{$\mathrm{N}(\%)$} & \multicolumn{2}{|c|}{ Total FAHI } \\
\hline & & & Mean & SD \\
\hline \multirow[t]{4}{*}{ Age (Years) } & $18-30$ & $11(10.0)$ & 123.39 & 24.62 \\
\hline & $31-40$ & \multirow{5}{*}{$\begin{array}{l}44(40.0) \\
42(38.2) \\
13(11.8) \\
66(60.0) \\
44(40.0)\end{array}$} & 134.76 & 20.89 \\
\hline & $41-50$ & & 133.32 & 19.73 \\
\hline & More than 50 & & 133.93 & 14.87 \\
\hline \multirow{2}{*}{ Gender } & Male & & 134.83 & 18.82 \\
\hline & Female & & 130.18 & 22.11 \\
\hline \multirow[t]{3}{*}{ Marital status } & Unmarried & \multirow{5}{*}{$\begin{array}{l}6(5.5) \\
83(75.5) \\
21(19.1) \\
61(55.5) \\
49(44.5)\end{array}$} & 119.79 & 16.70 \\
\hline & Married & & 134.95 & 19.68 \\
\hline & Separated/Widowed & & 128.94 & 22.08 \\
\hline \multirow[t]{2}{*}{ Education level } & Up to 7 th Standard & & 132.19 & 18.25 \\
\hline & Above 7th Standard & & 133.95 & 22.61 \\
\hline \multirow[t]{7}{*}{ Types of occupation } & Casual Labourer & \multirow{8}{*}{$\begin{array}{l}17(15.5) \\
6(5.5) \\
38(34.5) \\
16(14.5) \\
23(20.9) \\
1(0.9) \\
9(8.2) \\
29(31.5)\end{array}$} & 126.73 & 16.73 \\
\hline & Agriculture & & 129.09 & 16.16 \\
\hline & Job & & 135.94 & 21.69 \\
\hline & Business & & 132.64 & 21.41 \\
\hline & $\begin{array}{l}\text { Work at Home or } \\
\text { Housewife }\end{array}$ & & 134.93 & 19.59 \\
\hline & Sex Worker & & 127.53 & \\
\hline & Doing Nothing/Retire & & 131.02 & 24.62 \\
\hline \multirow[t]{2}{*}{ Income (Rs) } & Up to 5,000 & & 132.89 & 23.50 \\
\hline & 5,001 to 10.000 & $43(46.7)$ & 129.70 & 20.28 \\
\hline
\end{tabular}




\begin{tabular}{|c|c|c|c|c|}
\hline & Above 10,000 & $20(21.7)$ & 142.43 & 15.26 \\
\hline \multirow[t]{4}{*}{ Alcohol consumption } & $\begin{array}{l}\text { Every day or 2-3 Times a } \\
\text { Week }\end{array}$ & \multirow{12}{*}{$\begin{array}{l}4(3.6) \\
14(12.7) \\
4(3.6) \\
88(80.0) \\
7(6.4) \\
15(13.6) \\
59(53.6) \\
9(8.2) \\
16(14.5) \\
4(3.6) \\
35(31.8) \\
75(68.2)\end{array}$} & 138.63 & 25.82 \\
\hline & At Least once a Week & & 134.77 & 26.06 \\
\hline & $\begin{array}{l}\text { Did not Drink in last } 4 \\
\text { Week }\end{array}$ & & 136.71 & 13.91 \\
\hline & Never & & 132.26 & 19.46 \\
\hline \multirow[t]{6}{*}{ Living arrangement } & Alone & & 126.41 & 29.07 \\
\hline & With Spouse & & 129.88 & 20.90 \\
\hline & With Spouse and Children & & 134.72 & 19.97 \\
\hline & With Parents & & 132.56 & 18.24 \\
\hline & With Son/Daughter & & 131.95 & 20.67 \\
\hline & With Spouse\& Parents & & 135.30 & 13.76 \\
\hline \multirow[t]{2}{*}{ Migrant } & Yes & & 135.89 & 22.14 \\
\hline & No & & 131.61 & 19.28 \\
\hline
\end{tabular}

Table 2:- Mean scores of FAHI questionnaire, based on clinical variables $(\mathrm{N}=110)$

\begin{tabular}{|c|c|c|c|c|}
\hline \multicolumn{2}{|l|}{ Variables } & \multirow[t]{2}{*}{$\mathrm{N}(\%)$} & \multicolumn{2}{|c|}{ Total FAHI } \\
\hline & & & Mean & SD \\
\hline \multirow[t]{3}{*}{ Duration of Illness (Months) } & 12 to 30 & \multirow{9}{*}{$\begin{array}{l}13(11.8) \\
24(21.8) \\
73(66.4) \\
17(15.5) \\
24(21.8) \\
69(62.7) \\
14(12.7) \\
38(34.5) \\
58(52.7)\end{array}$} & 123.11 & 15.47 \\
\hline & 31 to 60 & & 129.55 & 15.70 \\
\hline & Above 60 & & 135.86 & 21.70 \\
\hline \multirow{3}{*}{$\begin{array}{l}\text { Duration on ART treatment } \\
\text { (Months) }\end{array}$} & 12 to 30 & & 122.87 & 20.72 \\
\hline & 31 to 60 & & 132.31 & 16.10 \\
\hline & Above 60 & & 135.70 & 20.84 \\
\hline \multirow[t]{3}{*}{ CD4 Count (mm/cub) } & Less than 250 & & 128.10 & 21.77 \\
\hline & 250 to 500 & & 132.08 & 19.33 \\
\hline & Above 500 & & 134.74 & 20.56 \\
\hline
\end{tabular}

There was no significant difference FAHI score in Table 3 shows the overall means of total FAHI and its domain scores. If the mean domain scores were taken as the percentage of the highest score for their respective domain, the subjects scored most poorly in the emotional domain (66\%), followed by the social domain (76\%) which closely followed by functional and global domain (77\%). They seemed to be best in the physical function, the percentage of which was higher than that of the total FAHI score. The QOL scores of all four domains were positively correlated with the total measure of the quality of life (Spearman's rho ranging from 0.21 to 0.75 ). The strongest correlation was seen in the Functional and global well-being domain (Spearman's rho 0.75) (Table 3).

Table 3:- Mean and SD of FAHI domain score and score range

\begin{tabular}{|l|l|l|l|}
\hline FAHI \&Dimension & Mean(SD) & Score range & $\begin{array}{l}\text { Correlation with Total } \\
\text { FAHI }\end{array}$ \\
\hline FAHI Total & $132.97(20.23)$ & $0-176(75.55 \%)$ & \\
\hline Physical well-being (PWB) & $32.45(6.43)$ & $0-40(81.13 \%)$ & $\begin{array}{l}.699^{* *} \\
0.00\end{array}$ \\
\hline Emotional well-being (EWB) & $26.42(7.90)$ & $0-40(66.05 \%)$ & $\begin{array}{l}.671^{* *} \\
0.00\end{array}$ \\
\hline Functional and global well-being (FGWB) & $40.21(7.38)$ & $0-52(77.32 \%)$ & $\begin{array}{l}.755^{* *} \\
0.00\end{array}$ \\
\hline Social well-being (SWB) & $24.40(6.80)$ & $0-32(76.25 \%)$ & $.628^{* *}$ \\
\hline Cognitive functioning (CF) & & & 0.00 \\
\hline
\end{tabular}

** Correlation is significant at 0.01 level (2-tailed)

* Correlation is significant at 0.05 level (2-tailed) 
Participants didn't score higher in that domain which was maximally correlated with the total score of FAHI. As shown in table 3, there was least correlation of cognitive domain with total FAHI score $(\mathrm{r}=0.219)$ but in emotional domain, participants score is very high (79\%). Similarly, the paradoxical result found in PWB domain score with its correlation with total FAHI score.

Table 4:- Significant difference of the domains of quality of life (PWB, FGWB, SWB and CF scores of FAHI) and demographical data using ANOVA

\begin{tabular}{|c|c|c|c|}
\hline Variables & 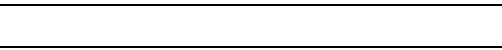 & F value & $\mathrm{P}$ value \\
\hline \multirow[t]{2}{*}{ SWB } & $\begin{array}{l}\text { Living Arrangement } \\
\text { - } \text { Alone } \\
\text { - With spouse } \\
\text { - With spouse and children } \\
\text { - With son/daughter } \\
\text { - With spouse and parents }\end{array}$ & 2.414 & 0.041 \\
\hline & 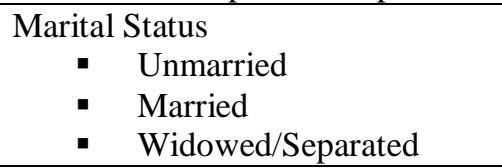 & 7.54 & 0.001 \\
\hline \multirow[b]{2}{*}{ FGWB } & $\begin{array}{cl}\text { Gender } & \\
\text { - } & \text { Male } \\
\text { - } & \text { Female }\end{array}$ & 4.001 & 0.048 \\
\hline & $\begin{array}{cl}\text { Duration on ART(months) } \\
\text { - } & 12 \text { to } 30 \\
\text { - } & 31 \text { to } 60 \\
& \text { More than } 60 \\
\end{array}$ & 3.403 & 0.037 \\
\hline $\mathrm{CF}$ & $\begin{aligned} & \text { Duration on ART } \\
& . 12 \text { to } 30 \\
& . 31 \text { to } 60 \\
& \text { - } \text { More than } 60\end{aligned}$ & 3.705 & 0.028 \\
\hline
\end{tabular}

$(\mathrm{PWB}=$ Physical well-being, $\mathrm{FGWB}=$ functional and global well-being, $\mathrm{SWB}=$ social well-being and $\mathrm{CF}=$ cognitive functioning)

Table 4 shows the significant differences of the demographic data in FAHI domain scores. None of the demographic data showed any difference with the total FAHI score. SWB domain score was significantly different in all three categories of marital status $(\mathrm{p}=0.001)$, followed by living arrangement $(\mathrm{p}=0.041)$, no other demographic variable showing the difference in score of social well-being. While FGWB domain score was significantly $(\mathrm{p}=0.048)$ different between male and female. And along with FGWB domain, cognitive functioning domain shows a significant difference $(\mathrm{p}=0.037 \& \mathrm{p}=0.028$, respectively) with duration of taking ART.

There was no significant difference between genders in association with the overall QOL. Physical domain score was same in related to all demographic information. Social well-being score was significantly different in living arrangement $(\mathrm{p}=0.041)$ and marital status $(\mathrm{p}=0.001)$. Male and female had a significant difference $(\mathrm{p}=0.048)$ in FGWB domain only. While FGWB and CF domain score was significantly different $(\mathrm{p}=0.037, \mathrm{p}=0.028)$ in the duration of taking ART.

\section{Discussion:-}

This study was aimed at assessing the quality of life of people living with HIV/AIDS. The total FAHI and domain scores in this study were similar to those reported in the validation paper by Peterman et al. ${ }^{\text {(Peterman, Cella \& McCain 1997) }}$

The average age of participants was $41.27 \pm 8.44$ years and the largest group was $31-40$ years. The number of males and females were $66 \%$ and $44 \%$. Most of them were married $(75.5 \%)$. Just above to half $(55.5 \%)$ respondents' education levels were up to the seventh standard. Duration of illness increases the average score of FAHI also increases. There was not a large difference in FAHI score and CD4 count. 
Assessment of QOL consist well-being in all dimension of health (physical well-being, emotional well-being, functional and global well-being, social well-being and cognitive functioning). In our study, about three-quarters $(70.9 \%)$ of respondents score more than 121 , while only $20.1 \%$ respondents were scored between 61 to 120 and nobody with the score below 60 (total score of FAHI is 176). Previous studies had shown the lack of a relation between gender and quality of life (Susan et al. 1999) (Burgoyne \& Saunders 2001) , and in another study, a worse physical quality of life was observed in women ${ }^{\text {(Hays et al. n.d.) }}$

Based on the average value of the all five domains of QOL, physical well-being domain (81.13\%) showed the highest value, followed by cognitive functioning (79.08\%), Functional and global well-being(77.32\%) and Social well-being(76.25\%) which indicate a better quality of life in these domains, then and the lowest values in the emotional well-being domain (66.05\%). However, C. I. Hasanah et al ${ }^{\text {(Hasanah, Zaliha \& Mahiran 2010) }}$ (2010), got the highest value on the physical well-being domain (77\%), followed by cognitive functioning and FGWB, and then the lowest in the social well-being $(52 \%)$. Various social problems faced by PLWHA such as social stigma, poverty, depression, violence, and cultural beliefs will affect the QOL. But, Wig et al (Naveet et al. 2006) (2006) got the highest value in the social relationships domain and the lowest value in the environment domain. HIV/AIDS affects not only on physical health but also mental and social health, and then it can cause various problems affecting daily activities and patients interest (Naranjo \& Aranda 2004)

Post-hoc analysis between the score of social well-being domain and living arrangement showed that married people had a highest SWB score compare to people who are unmarried or separated/widow. This result might be because of moral support from a partner. Similarly, those who staying alone also had poor SWB score and those people who are in living with their spouse, children, and parents. Male were higher FGWB score (mean=41.34) compare to female (mean=38.5). This domain includes the ability to work, enjoying life, coping and acceptance of illness and motivated to do the things. So male is more fulfilling in their life compared to female.

\section{Conclusion:-}

Since many factors influence the quality of life, various facets of different domains have been examined. The overall quality of life of PLHAs was good as evident by the study. It was found that SWB, FGWB, and CF were controlled by the demographical or clinical variable such as living arrangement, marital status, and duration of taking ART. Even though PLHAs had better scores in physical and cognitive functioning domains they face difficulties in their emotional aspects.

The results from this study suggest that PLHIV should receive better psycho-education and psychological intervention to improve insight and emotional well-being.

\section{Limitation:-}

The small sample size in the study was estimated on the assumption that not many PLWHA would have a good perception of their quality of life; future studies should involve a larger sample size. The study had limitations like stipulated time frame, selecting the patients from the single center by purposive sampling. As a consequence, the result of this study cannot be generalized across India.

\section{Acknowledgments:-}

This study was approved by the institutional Ethical Committees and permitted by NACO. We are grateful to the Gujarat State AIDS Control Society and Community care and Support Centre (CSC), Surat. We also thank the participants and the staff of CSC. We wish to express our heartfelt gratitude to Dr. A. Thangamani Ramalingam for helping us constructing this research study.

Disclosure:- The authors report no conflicts of interest in this work. 


\section{Bibliography:-}

1. Bozzette, S, Hays, R, Berry, S, Kanouse, D \& Wu, A 1995, 'Derivation and properties of a brief health status assessment instrument for use in HIV disease', J Acquir Immune Defic Syndr Hum Retrovirol, vol 8, pp. 253-65.

2. Burgoyne, R \& Saunders, D 2001, 'Quality of life among urban Canadian HIV/AIDS clinic outpatients.', Int J STD AIDS, vol 12, pp. 505-512.

3. Call, SA, Klapow, JC, Stewart, KE, Westfall, AO, Malinger, AP \& Demasi, RA 2000, 'Health-related quality of life and virologic outcomes in an HIV clinic', Quality of Life Research, vol 9, pp. 977-985.

4. Chan, K \& Revicki, D 1998, 'Changes in surrogate laboratory markers, clinical endpoints, and health-related quality of life in patients infected with the human immunodeficiency virus', Eval Health Prof., vol 21, pp. 26581.

5. Ganz, P, Schag, C, Kahn, B \& Petersen, L 1994, 'Assessing the quality of life of HIV infected persons: clinical and descriptive information from studies with The Hopes', Psychol Health, no. 9, pp. 93-110.

6. Globe, D, Hays, R \& Cunningham, W 1999, 'Associations of clinical parameters with health-related quality of life in hospitalized persons with HIV disease', AIDS Care, vol 11, pp. 71-86.

7. Hasanah, CI, Zaliha, AR \& Mahiran, M 2010, 'Factors influencing the quality of life in patients with HIV in Malaysia', Qual Life Res.

8. Hays, R, Cunningham, W, Sherbourne, C, Wilson, I, Wu, A \& Cleary, P, 'Health-related quality of life in patients with human immunodeficiency virus infection in the United States: Results from the HIV cost and services utilisation study.', Am J Med, vol 108, pp. 714-722.

9. Murri, R, Fantoni, M, Borgo, C, Visona, R, Barracco, A \& Zambeli, A 2003, 'Determinants of health-related quality of life in HIV-infected patients', AIDS CARE, vol 15, no. 4, pp. 581-590.

10. Naranjo, B \& Aranda 2004, 'Quality of life in HIV-positive patient', J Assoc Nurses AIDS Care, vol 15, pp. 2027.

11. Naveet, W, Raja, L, Hemraj, P, Vivek, A \& Chander, M 2006, 'The Impact of HIV/AIDS on The Quality of Life: A cross section study in north india', Indian Journal of Medical Sciences, vol 60, no. 1, pp. 3-12.

12. Peterman, AH, Cella, DF \& McCain, N 1997, 'Psychometric validation of the revised Functional Assessment of Human Immunodeficiency Virus Infection (FAHI) quality of life instrument', Quality of Life Research, vol 6, pp. 572-584.

13. Susan, S, Mohr, J, Justis, J, Berman, S, Squier, C, Wagener, M \& Singh, N 1999, 'QOL in patients with human immunodeficiency virus infection: impact of social support, coping style and hopelessness.', Int J STD AIDS, vol 10, pp. 383-91.

14. Wilson, I \& Cleary, P 1995, 'Linking clinical variables with health-related quality of life: a conceptual model of patient outcomes', JAMA, vol 273, pp. 59-65.

15. Wu, A, Hays, R, Kelly, S, Malitz, K \& Bozzette, S 1997, 'Applications of the medical outcomes study healthrelated quality of life measures in HIV/ AIDS', Qual Life Res., vol 6, pp. 531-554.

16. Yen, C, Tsai, J, Lu, P, Chen, Y \& Chen 2004, 'Quality of life and its correlates in HIV/AIDS male outpatients receiving highly active antiretroviral therapy in Taiwan', Psychiatry and Clinical Neurosciences, vol 58, pp. 501-506. 